\title{
PODER Y CULTURA POPULAR EN CARTAGENA, 1900-1930: ¿TRANSGRESIÓN O NEGOCIACIÓN?
}

\author{
Javier Ortiz Cassiani *
}

Para Yasmina Tippenhauer,

quien demuestra que el Caribe es un sentir.

El presente material tiene los limitantes del ensayo (en su acepción de experimento), un acercamiento iniciático, azaroso, no reposado. Más que certezas o hipótesis bien fundadas constituye sólo unas notas pergeñadas, leves intuiciones surgidas en el proceso de elaboración de nuestro trabajo de grado para optar el título de magister, que espero, se enriquezca con los aportes de los lectores.

En él, exploraremos las formas de manifestación del poder, su puesta en escena en Cartagena de Indias, un espacio vinculado geoestratégica y culturalmente al gran Caribe insular; las negociaciones que este poder experimenta dadas las características económicas de la ciudad; y la relación entre el poder, la élite y los sectores populares, marginados, subalternos, o como prefiera llamárseles. Si bien la periodización alude a los tres primeros decenios del siglo XX, nuestra mirada se desplazará a tiempos más remotos, pues siempre que se entra en los complejos terrenos de las prácticas culturales, la periodización constituye, casi siempre, una necesidad metodológica, y el análisis en la mayoría de los casos sólo tiene sentido

\footnotetext{
* Historiador, egresado del Programa de Historia de la Facultad de Ciencias Humanas de la Universidad de Cartagena. Candidato a Magister por la Universidad Internacional de Andalucía, España.
} 
a partir de la larga duración. De manera que las referencias al período colonial y al siglo XIX serán una constante.

Abordaremos el concepto de cultura — siguiendo a Peter Burke — como un "sistema de símbolos, significados, actitudes, y valores compartidos" por una determinada sociedad. Estas manifestaciones sin embargo, no tienen un carácter homogéneo, en su interior existe un mundo de contradicciones. Su sentido de movilidad se puede apreciar en los planteamientos de Clifford $\mathrm{Geertz}^{2}$, (autor sustancial de la renovación en el concepto de cultura), quien afirma que, "el análisis de la cultura ha de ser no una ciencia experimental en busca de leyes, sino una ciencia interpretativa en busca de significaciones", con ello le otorga una función dinámica y la libra de la "fosilización" en que la habían sumido estudios anteriores.

El concepto de cultura popular lo plantea Burke en su sentido gramsciano, por oposición a la cultura hegemónica, la de los grupos que no forman parte de la élite. Ambos autores, Burke y Gramsci, son claros en no ver lo anterior como una dicotomía simplista. Si bien se es consciente de la existencia de una cultura hegemónica, no se es menos consciente de las zonas de confluencia entre estas dos formas de percepción de concebir la realidad; lo popular no está ajeno al proyecto hegemónico, representa intereses que, de alguna manera, también son reconocidos por las clases subalternas. Esto ha permitido desdibujar la concepción de cultura popular como simple receptora/opositora y a la cultura hegemónica como impositiva. La mirada en los últimos tiempos se inclina, más que hacia las diferencias irreconciliables —en muchos casos maraqueas - , hacia las formas de recepción, apropiación, negociación, complicidad, y resemantización; así mismo a los intercambios y circularidades ${ }^{3}$.

1 BURKE, Peter, La Cultura Popular en la Europa Moderna, Madrid, Alianza Editorial, 1991, p. 29. Teniendo en cuenta las observaciones que le hace Edwar Palmer Thompson en el texto Costumbres en Común, Barcelona, Crítica, 1991.

2 GEERTZ, Clifford, La Interpretación de las Culturas, México, 1987.

3 BURKE, Op. Cit. ; para analizar la interpretación que Gramsci hace de la cultura, véase MARTÍNBARBERO, Jesús, De los Medios a las Mediaciones, Santafé de Bogotá, Convenio Andrés Bello, 1998. 
Para acercarnos al concepto de poder hemos seguido el interesante texto de George Balandier, El poder en escena: de la representación del poder, al poder de la representación; para este autor el poder es una constante puesta en escena, una teatralización, una representación que se expresa por medio de conmemoraciones, monumentos, discursos, himnos, cantos, desfiles, exposiciones. Intenta mostrar una imagen sublime, magnificada de la sociedad, a través de la espectacularización de los actos. Representaciones que a su vez implican separación, distancia, jerarquías ${ }^{4}$.

Michel Foucault, entre tanto, dice que el poder no sólo se asume a partir de las normativas del estado, sino a partir de los ejercicios de control, que intentan poner en circulación los sectores hegemónicos en los planos económico y social. El poder no sólo se ejerce impositivamente de arriba hacia abajo, su aplicación demanda negociaciones con las instancias aparentemente obligadas a someterse ${ }^{5}$.

Relacionando los conceptos expresados de cultura con las visiones acerca del poder, nuestro objetivo ahora es analizar cómo a partir de la idea de Cartagena en el espacio caribeño, ese poder está en constante negociación, dadas las prácticas económicas, políticas y culturales del Caribe; de igual modo la relación entre la élite o los grupos hegemónicos, y la cultura popular.

En algunos pasajes utilizaremos el nombre de Cartagena, indistintamente de nuestra ubicación temporal en la Colonia, la República, o el siglo XX. Valga aclarar, que cuando lo hagamos para el caso colonial y gran parte del siglo XIX nos estaremos refiriendo a la provincia de Cartagena, que comprendía los territorios que limitaban al norte con la costa del mar Caribe, al oriente con el Río Grande de la Magdalena, al occidente con el río Darién o Atrato y al sur con los límites naturales de las serranías de Ayapel y San Lucas. Lo que en la actualidad constituye los departamentos de Bolívar, Atlántico, Sucre, Córdoba, y parte de Antioquia (Urabá). En el caso de fines del siglo XIX y principios del siglo XX, entenderemos por

4 BALANDIER, George, El Poder en Escena, De la Representación del Poder al Poder de la Representación, Barcelona, Paidós, 1994.

5 FOUCAULT, Michel, Un diálogo sobre el Poder, Madrid, Alianza Editorial, 1985. 
Cartagena sólo el espacio urbano específico, esto es, los barrios intramuros: la Catedral, Santo Toribio (San Diego), la Trinidad (Getsemaní); los extramuros: (que oficiaban al principio como corregimientos) Manga, Pie de la Popa, Cabrero, Espinal, Lo Amador, La Quinta, Pueblo Nuevo, Boquetillo, Chambacú y posteriormente Bocagrande.

\section{EL CARIBE, ENTRE LA TRANSGRESIÓN Y LA NEGOCIACIÓN}

Desde el umbral de la Conquista, y luego, durante la Colonización, se crea un espacio regional caribeño históricamente reconocible. A partir del asentamiento de los españoles en la isla de Santo Domingo, se generó un proceso expedicionario mediante el cual las islas caribeñas servían como sitios de avanzada para la explotación de nuevos territorios en tierra firme, tras las expectativas de riqueza que en forma de rumores llegaban a las islas $^{6}$. Estas expediciones españolas fueron dejadas, en su mayoría, a manos de la empresa privada.

Si bien fueron los españoles los que primero llegaron al espacio caribeño, muy pronto este territorio habría de convertirse en el escenario por excelencia de las luchas imperiales por el control económico y social de los nuevos territorios al otro lado del Atlántico. Por su vasto relieve el Caribe vería desfilar, junto a los españoles ya establecidos, a ingleses, franceses, holandeses, daneses, escoceses; posteriormente judíos, norteamericanos y sirio libaneses ${ }^{7}$.

\footnotetext{
6 Para un análisis de la formación de un espacio regional Caribe, véase VIDAL ORTEGA, Antonino, Cartagena de Indias en la articulación del espacio regional caribeño, 1580-1640: La producción agraria, Lebrija (Esp.), Agrija ediciones, 1998 y TOVAR, Hermes, La estación del miedo o la desolación dispersa. El Caribe en el siglo XVI, Ariel, Santafé de Bogotá, 1998.

7 En el siglo XVIII, el padre Antonio Julián se quejaba de la influencia religiosa que los imperios extranjeros ejercían en los grupos indígenas y colonos españoles en el territorio de la Guajira. Don Antonio Julián. La Perla de América. Provincia de Santa Marta, Bogotá, Biblioteca Popular Colombiana, 1951; para un acercamiento a la influencia norteamericana en la vida caribeña, véase las memorias del coloquio "El Caribe entre Imperios" realizado en mayo de 1994 en la Universidad de Princeton, Arcadio Díaz Quiñones (editor) Op. Cit, Revista Centro de Investigaciones Históricas, Departamento de Historia, Universidad de Puerto Rico, número 9, 1997; un análisis de la influencia árabe y judía en el Caribe colombiano se puede encontrar en: Louise Fawcetty Eduardo Posada Carbó,
} 
De tal manera que el concepto de soberanía imperial se va a ver altamente trastocado por el peso de las acciones de los múltiples imperios concentrados en un espacio reducido. En 1762, para colocar sólo el ejemplo más estudiado, Cuba, posesión española sufre la invasión militar de la Corona Británica. La amenaza a la soberanía imperial obligará a la toma de medidas orientadas a la salvaguarda y vigilancia de los territorios. En el siglo XVIII, a tono con las políticas borbónicas, se empezaron a organizar batallones fijos en las principales ciudades del Caribe: La Habana en 1719, Cartagena de Indias en 1736, Santo Domingo en 1738, Veracruz en 1740, y Panamá y San Juan en 1741. Una vez negociado el sitio de La Habana con los ingleses, los Borbones emprenden un largo proceso de reorganización de sus defensas, representada en una reforma militar, encomendada al mariscal de campo O' Really y al conde Riela.

Uno de los elementos centrales de la política borbónica en su afán por controlar sus posesiones en América era la hispanización de las principales instituciones en las colonias, a través del reemplazo de los criollos americanos por funcionarios españoles. El ejército no escapaba a esta tendencia, de manera que dentro de las exigencias de la Reforma Militar emprendida por O'Really y Riela, la "desamericanización" del ejército era el elemento central. Los inconvenientes con los que tropieza esta medida, y la necesidad de buscar otras vías de solución, nos empieza a abrir el camino y nos acerca al propósito de este trabajo, en tanto que pone en el tapete la constante negociación a la que tuvo que enfrentarse el poder de la monarquía en sus colonias americanas y específicamente caribeñas.

Debido a la falta de dinero, y a la escasez de hombres peninsulares para ser enviados a América, las intenciones iniciales de la Reforma Militar fracasaron. España bajo el régimen borbónico, tuvo que superar sus prejuicios contra los criollos americanos para poder atenderlas apremiantes necesidades defensivas. Contrario a la hispanización pretendida, lo que sucedió fue una americanización paulatina del ejército colonial; para 1740

\footnotetext{
"Árabes y Judíos en el Desarrollo del Caribe Colombiano, 1850-1950" y Adelaida Sourdis Nájera, "Los Judíos Sefardíes en Barranquilla", el caso de Jacob y Ernesto Cortissoz, en: Boletín Cultural y Bibliográfico, Banco de la República, Número 49, 1998, pp. 3-47.
} 
el número de oficiales criollos en el ejército era del 34\%, para 1760 del $33 \%$, y para 1800 , llegaba ya a la estimable cifra del $60 \%{ }^{8}$.

Si esto constituía un problema inevitable para la corona, el verdadero inconvemente, estaba representado en la necesidad de crear milicias como complemento del ejército regular. De ahí que el principal elemento para la salvaguarda del poder del imperio, la representación encargada de mantener el control y el orden, exhibiría toda esa mixtura de colores que se había desarrollado en el Caribe, ante la marcha avasallante del mestizaje. Además, —como si fuera poco- "como estímulo para facilitar el reclutamiento, se concedió a los miembros de la milicia el fuero militar, status que daba a los criollos, y en cierta medida incluso a la población de raza mixta, los privilegios e inmunidades de que gozaban los militares españoles, sobre todo la protección de la legislación militar y un cierto grado de exención fiscal" "9.

Aparte de la violación de la soberanía en sentido político, como lo demuestra el caso de la penetración inglesa en Cuba, ocurre otra forma de ponerla en entredicho, ligada a formas no oficiales, no regladas, conducidas por personas, cuyos afanes comerciales sobrepasan el discurso imperial, y que como hemos venido diciendo, constituye otro elemento fundamental en los entresijos de negociación del poder. Así, en las zonas donde el Estado imperial ejercía poco control, se crean dinámicas culturales alternas a los poderes reglados. Antonio Benítez Rojo en la introducción a su prolífico libro "La Isla que se repite", , nos muestra cómo en Cuba al margen de la gran plantación esclavista, se crea una economía de contraplantación, que cobija relaciones comerciales, pero también y sobre todo culturales, del cimarronaje, sin órdenes $m$ jerarquías, distantes de los intentos de control de la plantación. Esta cultura se nutre de la puesta en escena de actitudes y aptitudes diversas; una cultura desacralizada, desritualizada, un cruce constante de diversas etnias, una cultura de hibrideces, que según el autor,

8 LYNCH, John. El SigloXVIII, Historia de España, Barcelona. Crítica, 1991, p. 307.

9 LYNCH. Op. Cit, p. 307.

10 BENÍTEZ ROJO, Antonio, La isla que se repite, el Caribe en la perspectiva posmoderna. Cuba, 1991. Introducción. 
es la que más aporta en la formación de los rasgos culturales y artísticos de Cuba y del Caribe en la medida en que es un fenómeno concomitante en toda el área geográfica caribeña.

De esta dinámica que se presentaba en el Caribe insular, Cartagena no es ajena. Sitio geoestratégico para las huestes en la búsqueda de oro en los territorios de las sabanas del Sinú, luego de su fundación en 1533, la ciudad se encuentra con el problema de la falta de un hiterland capaz de abastecerlo de las necesidades que demanda su condición de puerto. Esto la obliga a mirar hacia el Caribe insular con el que sostiene un próspero comercio, de manera que desde un principio Cartagena oficia como una ciudad puerto con todo lo que económica y culturalmente ello implica. Crece mirando hacia las aguas de tonos azul verdoso del mar Caribe y, hasta cierto punto, de espaldas al interior del país. El $90 \%$ del tráfico comercial del puerto de Cartagena en el siglo XVII, se efectúa con el espacio regional caribeño, y sólo un ínfimo $10 \%$ con el interior del Nuevo Reino $^{11}$.

Una de las constantes en la historia de la provincia de Cartagena, es la dispersión de la población y la proliferación de palenques y rochelas. Los obispos asignados para la plaza de Cartagena y los visitadores, se quejaban de forma reiterativa de la proliferación de rochelas en el territorio de la provincia, quienes la veían, - así en efecto era-, como un territorio de costumbre relajadas, entregado a bailes lascivos y al consumo permanente de alcohol, alejados de los deberes para con Dios, sin obediencia al toque de campanas. Para tratar de evitar este flagelo, la administración borbónica organizó cuatro expediciones a lo largo de todo el territorio de la costa Caribe. La primera de ellas se organizó en la provincia de Santa Marta, a cargo del maestre de campo José Fernando de Mier y Guerra, entre 1744 y 1770; la segunda, que data de 1745, en los territorios de Tierradentro, fue ejecutada por Francisco Pérez de Vargas, la tercera, a cargo del teniente coronel Antonio de la Torre y Miranda en las sabanas de la provincia de Cartagena, abarcó el período de 1774 a 1779; la cuarta y última, considerada quizá la más importante, emprendida en los territorios de San

\footnotetext{
${ }^{11}$ Véase VIDAL, Antonino, Op. Cit., p. 98.
} 
Jorge, Nechí y el Cauca, en los años de 1787 y 1788 por Joseph Palacio de la Vega, un cura franciscano polémico y temerario, que mataba tigres, engañaba con relojes a los indios incautos y casaba a cuanto amancebado encontraba en sus travesías. En sus afanes por congregar a la población dispersa, a los "arrochelados", al "toque de campanas", Palacio nos dejó un excepcional documento, que refleja las costumbres y hábitos de los pueblos que va congregando ${ }^{12}$.

Los resultados de las expediciones no son nada desdeñables, "según lo que sabemos, estas cuatro expediciones permitieron el agrupamiento y reagrupamiento de más de sesenta pueblos y de cerca de sesenta mil habitantes de todas las castas: blancos, negros, indios, mestizos, zambos y mulatos. Sólo Antonio de la Torre fundó treinta y tres pueblos, refundo once y permitió la incorporación a la vida civil de al menos cuarenta mil españoles, mestizos, negros y mulatos" ${ }^{\prime 3}$. Sin embargo, pese a estos resultados, el problema no se pudo extirpar, siguió permeando la vida de la provincia de Cartagena. Se estima que para finales del siglo XVIII, aproximadamente el $30 \%$ del total de su población se encontraba en estado de dispersión, de modo que las rochelas, los palenques, los indios rebeldes, no constituían una nota sui géneris, la marginalidad era una característica central del modo como operaban estas sociedades. De hecho, desde sus comienzos, el proceso de poblamiento en la costa Caribe era bastante escaso, y el poco que existía, se había realizado de manera espontánea, con poca o ninguna intervención de las autoridades españolas. Reflejaba la creación de elementos de poder autónomos al margen de la oficialidad hispánica, se fueron creando instancias propias de poder con las cuales tuvo que negociar la monarquía española, cuando bajo la administración borbónica intentó meter en cintura a un remo que se le escurría de las manos.

\footnotetext{
${ }^{12}$ PALACIO DE LA VEGA, Joseph, Diario de viaje entre los indios y negros de la provincia de Cartagena en el Nuevo Reino de Granada, 1787-1788, Bogotá, 1955.

${ }^{13}$ MUÑERA, Alfonso, El fracaso de la nación, región, raza y clase en el Caribe colombiano, (17171810), Santafé de Bogotá, Banco de la República/Ancora Editores, 1998, pp. 61-62.
} 
La negociación se hará nuevamente presente. El 3 de diciembre de 1815 en el período de la reconquista española, proveniente de Zacatecas, fue nombrado quien sería el último gobernador de la provincia de Cartagena en el período colonial, Brigadier Gabriel Ceferino de Torres y Velasco, quien se posesionó el 3 de diciembre de 1815, y el 2 de mayo de 1816 el Rey lo nombra además comandante General de Cartagena de Indias y subinspector de las tropas del Nuevo Reino de Granada. En esta doble función, Torres y Velasco, afrontó un incremento de las rochelas que se infiere por el alarmante descenso de la población; de 9.622 habitantes, según el censo de 1778, descendió a 4.866 habitantes en 1825, lo que indica una reducción del $50 \%{ }^{14}$. Emprendió una entusiasta campaña de control de las rochelas, las fugas y el cimarronaje. Tal vez por el temor a un nuevo levantamiento en contra del estado español, Torres, fue consciente de las necesidades de la negociación antes de la represión en la idea de someter a los dispersos al orden y a la ley El 8 de enero de 1816 editó "El Bando del buen gobierno", que hizo circular por toda la provincia. En él marcaba las pautas de lo que debían ser las relaciones al interior de la provincia, en uno de los apartes del bando reza lo siguiente:

A los fines expresados no conduce el rigor, y por lo tanto el comandante, sin despojarse de firmeza y entereza que debe señalar a un militar y magistrado será afable, civilizado y humano, distinguirá a la clase principal en su trato y mantendrá un porte sostenido, aunque sin orgullo con la plebe y en tal forma será amado, respetado y temido generalmente $^{15}$.

Había que tratar de mantener una conducta cordial con los sectores marginados, "sin orgullos con la plebe", constituida por toda esa amalgama de gentes de todos los colores, que habitaban no sólo los territorios de la provincia, sino también, el centro urbano. Cartagena, que en razón a su condición de puerto, sus constantes ferias comerciales en la colonia, su incorporación en la ruta de los galeones, y ser el principal puerto negrero en

14 BELL LEMUS, Gustavo, "Deserciones, fugas, cimarronajes, rochelas y uniones libres: el problema del control social en la provincia de Cartagena al final del dominio español, 1816-1820", en: Cartagena de Indias de la Colonia a la República, Bogotá, Fundación Guberek, p. 78.

15 Ibid. Las cursivas son nuestras. 
América; había desarrollado una cultura cosmopolita, una ciudad de mucho movimiento y ruido, crisol de costumbres diversas, una constante feria humana, la ciudad vivía un carnaval incesante. Los términos: afable, humano, civilizado, moderación, suavidad, prudencia; que constituyen una idea de la negociación, serán los más usados por este funcionario en su discurso. Pareciera que traicionara la supuesta radicalidad con la que habían sido preconizadas las reformas borbónicas. La situación real, la cotidianidad de la provincia, no le dejaba otra alternativa. En octubre de ese mismo año (1816), le comunicaba al capitán a guerra de Barranca, que obligara a los vecinos de Pedraza, arrochelados en los montes de su jurisdicción, para que se establecieran en el poblado; operación que sin embargo debía hacerse con:

"Mucha moderación y suavidad a efecto de que no padezca detrimento alguno de sus bienes, siembras y ganados, prefijándoles tiempo proporcionado y oportuno para su recolección, persuadiéndoles con la misma suavidad, que conviene a sus intereses que se reduzca a poblado"16.

La alternativa era la negociación, el poder como afirma Deleuze, "es — ante todo- una estrategia, algo que está en juego"17 que se vale de los mecanismos de persuasión, como en toda negociación algo se pierde y algo se gana. Si el mismo gobernador de la provincia imponía como dinámica de control de sometimiento de la población la negociación, los jueces y alcaldes locales en cada una de sus jurisdicciones eran prácticamente soberanos. Herederos de una tradición pactista que le concedía autonomía a las localidades, en donde las disposiciones del Rey, podían ser cuestionadas si iban a contrapelo con los intereses específicos de la zona, en tanto que se entendía a la monarquía, no en el sentido monista en que la concibieron los borbones, sino como una asociación de lealtades entre la corona y sus subditos. La venta de cargos oficiales es precisamente uno de esos

\footnotetext{
16 Ibid., p. 94. Las cursivas son nuestras.

${ }^{17}$ Primer postulado de Gilíes Deleuze, "postulado de propiedad" sobre el funcionamiento de las relaciones de poder, citado por Miguel Marey, en la introducción a Michel Foucault, Un diálogo sobre el Poder, Op. Cit.
} 
elementos que le otorga mayor autonomía a las administraciones en las colonias americanas ${ }^{18}$. El mismo gobernador Torres y Velasco, en marzo de 1819, le había comunicado al alcalde de Mahates:

"Que había tenido noticias de que en Ternera, Palenque y Gambote (...) hallan una decida protección de los esclavos cimarrones y toda clase de delincuentes, consistiendo aquella principalmente en la escandalosa tolerancia de los jueces de dichos sitios y en la criminal omisión con que miran el cumplimiento tan repetidamente encargado de las provincias de este gobierno" 19 .

\section{SOLDADOS, DESERTORES, POLICÍAS Y TRANSGRESIÓN: EL PROBLEMA DEL ORDEN}

A las autoridades coloniales y republicanas también les tocó lidiar con el problema de la deserción de las filas del ejército; este fenómeno parece ser una constante en el Caribe colombiano, con el agravante que quienes se escapaban iban a engrosar las filas de los dispersos y arrochelados y a vivir en amancebamiento con indias o negras de la región. Para fines del siglo XVIII, en su informe como congregador de pueblos, Antonio de la Torre y Miranda se quejaba del problema de las deserciones y de las dinámicas transgresoras que ello genera:

Descendiente de los desertores de tropa y marinería, de los muchos polizones...de los negros, esclavos y esclavas cimarrones que habiendo hecho algunas muertes o cometido otros delitos, buscaron el abrigo de sus excesos en las dispersiones.. .y muchos indios e indias que mezclados con mestizas negras y mulatas, propagaron una

18 Para un análisis de la forma de administración de los Habsburgos en las colonias americanas véase el interesante trabajo de Antonio Aninno "Soberanías en Lucha", en: De los Imperios a las naciones hispanoamericanas (comp), Forum International des sciences humaines, Zaragoza, 1994, cap. 8,pp. 229-253; Jhon Lynch, El Siglo . Op. Cit. pp.298-301. En 1750 se abole por parte de los borbones la venta de cargos, pero ante la crisis, económica de la metrópolis, esta práctica propia del sistema administrativo de los Habsburgos se vuelve a instalar.

19 Citado por BELL, Gustavo. Op. Cit., p. 94. Las cursivas nuestras. 
infinidad de castas difíciles de averiguar... que vivían con el mayor abandono, desidia y poltronería, entregados a la embriaguez y otros vicios propios de una vida libre ${ }^{20}$.

Uno de los problemas de la milicia creada en Cartagena en 1771 eran las deserciones constantes. En 1780, un funcionario español, se quejaba de cómo en esta ciudad, refiriéndose a Cartagena, "se aborrecen las milicias y a todos los que sirven en ella". En 1818 el mismo gobernador Torres y Velasco, se lamentaba de la forma en que algunos desertores eran escondidos y protegidos, y dudaba de la eficacia de los jueces en el castigo que les debían imprimir En una comunicación bastante enérgica al alcalde de Sincelejo, lo increpaba, por su falta de acción contra los desertores: “Cómo es posible que habiendo tantos desertores viviendo en esa población usted no haga nada para castigarlos?" 21 . Ante un tipo de relaciones con visos de laxitud, para los habitantes de la costa Caribe, la vida reglada, la disciplina del ejército, no les resultaba nada atractiva, independientemente de que fueran españoles o criollos quienes estuvieran al mando del aparato militar, el problema estaría siempre presente. Un periódico local en 1917, a través de un extenso artículo, manifestaba su descontento por la circulación de rumores sobre el ejército:

Anoche circuló en los barrios alejados del centro el rumor de que estaban reclutando para la expedición a San Andrés, con ese motivo muchos individuos no se atrevieron a salir de sus casas, y las madres y hermanas de cada cual andaban buscándolos para darle la fatal noticia y llevarlos a que se escondieran. Esas noticias tan descabelladas nos perjudican en todo sentido, porque de seguro habrán trascendido a las poblaciones vecinas, y ya comenzarán los campesinos a no quererse exponer viniendo a la ciudad a traer sus viandas.

Esta mañana amaneció en nuestras pizarras, escrita por algún desocupado... esta noticia "Colombia declaró la guerra a Nicaragua". Un abuso intolerable que debe castigarse con mano fuerte y que solo

20 DE LA TORRE, Antonio, "Informe sobre poblamiento de la provincia de Cartagena", citado por Alfonso Muñera El fracaso... Op. Cit., p. 73.

21 BELL, p. 83. 
se ve en estos días "sin luz y sin policía". Sepan los señores de las afueras y de las poblaciones vecinas, que no hay tales reclutamientos, ni tales declaraciones de guerra. Es una positiva lástima que nunca se pueda saber de dónde salen esas versiones alarmistas. .Han llegado hasta inventar que la luz eléctrica ha sido apagada deliberadamente para que se efectúen ciertos movimientos militares que el público no debe ver.

Anoche creían las gentes sencillas que a las 12 en punto iba a salir para las calles el batallón con sus cañones y sus caballos y todo..."22.

La reacción de rechazo de la población de los sectores populares, "las gentes sencillas" - como reza en el texto - de Cartagena y de la costa en general hacia las actividades castrenses era un hecho sumamente claro. Ante la posibilidad de ser reclutados para el préstamo del servicio militar, la fuga o la permanencia en sus casas serán las formas más convenientes como estrategias para la evasión de las obligaciones, hasta el punto que preocupa la escasez de alimentos que se pueda presentar en la ciudad ante el miedo de los campesinos a salir de sus parcelas para traer los productos agrícolas a la plaza de mercado. Es una reacción tan presente y conocida en la ciudad, que se usa para hacer bromas y causar el pánico.

Muchos no podían evadir el compromiso y tuvieron que asumir la vida militar, no obstante, protagonizarían escenas de desorden constante. La prensa cartagenera de finales del siglo XIX y principios del siglo $\mathrm{XX}$, se quejaba en forma reiterada de las trifulcas que armaban los miembros del ejército, sus andanzas por las calles en estado de embriaguez y de atentar contra la moral pública con sus actos vergonzosos:

El sábado por la noche se encontraba en la playa de Barahona una canoa arrimada y en el caramanchel se hallaba una sílfide a quien le hacía el amor un soldado perteneciente al Regimiento acantonado en esta plaza. Varios agentes de la policía se dieron cuenta del coqueteo

22A.H.C."La Alarma de Anoche”, La Época, 10 de octubre de 1917, p. 7, Tomo 15. 
de los galantes y sin llenar los requisitos del caso para allanar la embarcación abordáronla y trataron de aprisionar al soldado... ${ }^{23}$.

La noticia termina relatando un incidente donde inclusive hubo disparos por la negativa del soldado a dejarse atrapar. Como se puede observar, no sólo se condena la conducta asumida por el soldado, sino también la forma errónea en que procede la policía. Si bien el comandante de la policía critica a los soldados y los coloca en el papel de los mayores causantes de desorden en la ciudad, la prensa estará pendiente y denunciará constantemente, los incumplimientos de los agentes del orden. El mismo periódico, de manera bastante jocosa informaba sobre las "actividades" de un agente de policía:

No os cause sorpresa amable lector. Todas las mañanas veréis en el mercado el agente de policía Número 4 haciendo piropos, guiños de ojo, etc. a las chicuelas. Dicho agente cuenta con suerte, pues siempre le toca el puesto que le conviene. Lo felicitamos y le deseamos muchos triunfos en la carrera de don juan ${ }^{24}$.

Para completar el cuadro que se refiere a las actividades amorosas de la policía, para la misma fecha aparece la siguiente noticia:

Al señor comandante de la policía departamental llamamos la atención hacia ciertas incorrecciones del agente número 3, un señor Rodríguez, de quien se nos dice ha habilitado la correguiduría del Amador, donde permanece de puesto permanente, como su casa habitación, pues allí a mudado a una señora que se asegura ser su concubina ${ }^{25}$.

La corregiduría, el sitio que por naturaleza debe velar por el orden en cada uno de los barrios de la ciudad, es ocupado por el agente de turno para prácticas totalmente ajenas a su fin, además, de carácter transgresor, como el concubinato que parece ser un fenómeno natural. Al lado de esto se les acusaba de borrachos, dirigirse a la gente con insultos y no estar

23Archivo Histórico de Cartagena (en adelante A.H.C.) La Época, Cartagena, enero 4 de 1916. Tomo 10, p. 4.

24 A.H.C. La Época, Cartagena, 28 de julio de 1921, p. 4.

25 A.H.C.Op. Cit.,p. 8. 
oportunamente en el sitio indicado. Lo que podemos anotar aquí, es el hecho de que estas personas independientemente del uniforme, de la institución, manejan una serie de imaginarios adquiridos a lo largo de los años en un escenario donde las dinámicas culturales, por lo menos en su desarrollo cotidiano, eran sumamente laxas. Su manera de percibir la vida, su cultura, entraría pues en escena al momento de desempeñar sus labores.

\section{CONTRABANDO, MERETRICES Y FUNCIONARIOS}

Después, tras la eminente nulidad de un político, en la acera de enfrente luce su desparpajo una ramera.

Luis Carlos López "Mi española raza"

Debido a su posición geográfica el Caribe colombiano fue sitio por excelencia de contrabando. Esta actividad en Cartagena se hacía con absoluta impunidad, más que desde la visión del contrabando asociado al pirata furtivo y clandestino que se escurre por los puertos, al contrabando hay que mirarlo en la costa Caribe como una actividad inscrita dentro del acontecer cotidiano; de hecho, es el contrabando el que permite la incorporación de la costa al circuito de comercio mundial ${ }^{26}$. El contrabando estaría detrás de las grandes fortunas de la mayoría de los comerciantes de la costa caribe. Todos harían parte de sus circuitos, desde el esclavo o el

\footnotetext{
${ }^{26}$ Para un análisis del contrabando y su importancia en el Caribe y las colonias americanas, véase: MOUTOKIAS, Zacarías. Contrabando y control colonial. Buenos Aires entre el Atlántico y el espacio peruano en el siglo XVII. Buenos Aires, CEAL 1989, RAMOS, Feliciano, El contrabando inglés en el Caribe y el golfo de México, Sevilla Diputación Provincial de Sevilla, 1990; ARAUZ MONFANTE, Celestino, El contrabando holandés en el Caribe, siglo XVIII, Caracas, Academia Nacional de Historia, 1986; VILLALOBOS, Sergio, Comercio y contrabando en el Río de la Plata y Chile, Buenos Aires, Eudeba, 1965; ARTURO, Julián, La Perla de América la provincia de Santa Marta, Bogotá, Banco de la República, 1981 Para el caso colombiano véase: FALS BORDA, Orlando, Historia doble de la costa Mompox y Loba, Bogotá, Carlos Valencia Editores, 1987. Tomo I; GRAHN, Lance, Comercio Contrabando y Sociedad en la Nueva Granada, 1713-1763, Departamento de Historia, Universidad de Duke, 1985; MUÑERA, Alfonso, "El Caribe colombiano: autoridad y control social en una región de frontera", en: Op. Cit. cap. II, PP- e "Ilegalidad y Frontera", en: MEISEL, Adolfo (editor), Historia económica y social del Caribe colombiano, Barranquilla, Uninorte, 1994: DE POMBO, José Ignacio, El Informe del Real Consulado de Cartagena de Indias..., Bogotá, Procultura, 1986.
} 
peón que descargaba las mercancías, hasta los militares, obispos, y gobernadores. Un ejemplo interesante es el que se presenta con el gobernador de Cartagena, José de Zúñiga y Lazerda en los años de 1706 a 1713, quien dirigía personalmente el tráfico ilegal en cantidades alarmantes, provenientes de las colonias inglesas, francesas y holandesas. Por su parte el primer Virrey Jorge Villalonga, abusó tanto de esta actividad que la corona se vio inclusive en la necesidad de destituirlo y apresarlo en 1721, llegando a anular el recién creado Virreinato, que se restablece posteriormente bajo la administración de Sebastián de Eslava, en 1739.

En la costa Caribe y en Cartagena, el contrabando crea una serie de vínculos, un alto grado de aceptación y tolerancia. En el año de 1846, el periódico cartagenero "La Realidad", respondía a un editorial escrito por el director de su similar capitalino "Libertad y Orden", Alfonso Acevedo, quien se mostrara reacio a la declaración de Cartagena como puerto franco, y a la costumbre de los cartageneros de negociar con puertos extranjeros. Acevedo, tildaba a los cartageneros de picaros monopolistas, contrabandistas y egoístas. Acusaciones como éstas fueron frecuentes de parte de políticos y periodistas del centro del país a la ciudad de Cartagena. Lo que llama la atención es la manera como el periódico local responde a las acusaciones del diario capitalino. En ningún momento y pese a lo extenso del documento, se halla una frase directa y explícita que niegue la existencia del contrabando en la ciudad. El artículo se va por las ramas argumentando que es falso que en Venezuela no existan contrabandistas: “(...) pero lo que es del todo y evidentemente falso es aquello de que en Venezuela no haya tan escandalosos contrabandistas como en la Nueva Granada",27.

Casi un siglo después, en 1916, la historia se volvía a repetir. El periódico del "Tuerto" López, la "Unión Comercial", defendía a la ciudad de las acusaciones del periódico bogotano "El Nuevo Tiempo", que nos acusaba de "negros y contrabandistas" 28 . Las quejas del periódico local iban encaminadas a subrayar el hecho de que no se debía generalizar, puesto que

27 La Realidad, Cartagena jueves 11 de junio de 1846. Microfilmado Biblioteca Bartolomé Calvo. 28 A.H.C. La unión Comercial. Cartagena, 10 de enero de 1916, p. 2. 
con ello, el funcionario de Aduana, que por lo regular era del interior del país tomaría medidas "extremas", causando "perjuicio moral y material al comerciante honrado". Hasta el momento no aparece ninguna argumentación que niegue la existencia del ilícito, termina inclusive, aceptando su existencia:

No indica esto, por otra parte que nosotros queramos probar que el contrabando no deba combatirse en la costa; lejos de esto estamos convencidos de que ese mal está bastante arraigado $(\ldots)^{29}$.

Lo que no aceptan son la serie de medidas para evitarlo e insinúan que si bien éste no se da en Bogotá, no es precisamente por virtud, sino porque las condiciones topográficas no se lo permiten:

En el interior no existe contrabando como es sabido; allí únicamente se defraudan otras rentas públicas como en Cundinamarca sucede con licores nacionales. ¿Pero será acaso por virtud o porque las condiciones topográficas en que aquellas ciudades del interior se encuentran hacen que se cumpla el aforismo latino faceré de necesitare virtutem $?^{30}$.

El periódico "La Época", ese mismo año protestaba por una medida aduanera, que estipulaba la revisión de "todos los bultos declarados como equipajes de viajeros nacionales o extranjeros" ${ }^{31}$. Se acusaba al funcionario de Aduana de afectar el libre comercio y el desarrollo del puerto, los trabajos de los "honorables" comerciantes se verían opacados por la serie de prohibiciones burocráticas: "Los trabajos, ruidosos de la hoja periódica, y silencioso del hombre de negocios, nulos porque caen perdidos en el vacío de la abula oficinesca y en los torpes procedimientos oficiales"32.

De igual forma, otro periódico de la ciudad criticaba enérgicamente una medida aduanera que prohibía la arraigada costumbre de los cartageneros

29 Ibid.

30 A.H.C. La Unión Comercial, Op. Cit.

31 A.H.C. "Nuestro Puerto", La Época, Cartagena, 1 de mayo de 1916, pp. 2 y 7.

32 Ibid. 
de visitar los barcos cuando llegaban a puerto: “¿por qué se impide a una persona el derecho a visitar un barco por puro deporte? ? $^{33}$ El "puro deporte", era nada menos que el contrabando de menudeo, que junto al contrabando de grandes proporciones, se desarrollaba en la ciudad desde tiempos remotos, en el que personas sin distingos sociales, subían a los barcos a proveerse de perfumes, whiskys, cigarrillos, y toda clase de objetos de uso personal. Frenar aquello que hacía parte del diario vivir de los cartageneros, no podría causar sino reacciones de este tipo. Se veía como algo natural, sin visos delincuenciales, ninguna censura moral existía al respecto. La cotidianidad del contrabando la podemos apreciar en algunas crónicas de ilustres personajes cartageneros.

De manera que no parece tener nada de extraño, que un personaje como Manuel María Madiedo ${ }^{34}$, destacado cartagenero, prolífico escritor, autor de novelas, dramas, libros de poemas, tratados de crítica y ensayos de política, periodista, fundador de vanos periódicos a lo largo de toda la geografía nacional, en últimas, un hombre comprometido con el desarrollo del estado nación colombiano, escribiera una crónica titulada "El Contrabandista",35, en la que relata las aventuras de un grupo de guardias consoladores del contrabando, y lo que sucede cuando se encuentran con un grupo de contrabandistas. Lo que Madiedo nos deja ver es el grado de familiaridad que existe con la práctica del contrabando, los delincuentes parecen ser no los contrabandistas, sino aquellos guardias que terminan robándose las mercancías. El autor pone en boca de uno de los contrabandistas las siguientes palabras:

Con ustedes (los guardias) deberían cargar los demonios en cuerpo y alma, dijo la misma voz, ladrones hambrientos que viven del sudor de los demás hombres... no querrían nunca regalar infamemente a unos

33 A.H.C. "Una medida". La Unión Comercial, Cartagena, 14 de enero de 1916, p. 4.

34 Para revisar algunos datos de la vida de Madiedo, véase, MUÑERA, Alfonso (comp.) Ensayos Costeños, de la Colonia a la República, Santafé de Bogotá, Biblioteca de Autores Costeños, Colcultura, 1994, vol. 2, pp. 397-431.

35 MADIEDO, Manuel María, "El Contrabandista", en: Museo de Cuadros de Costumbres, Variedades y Viajes. Bogotá, Biblioteca Banco Popular, 1973. 
canallas el pan de mis hijos... Infames, este tabaco es el pan de seis hijos, de su madre, y de sus pobres abuelos que no pueden valerse" ${ }^{\text {, }}$.

Toda esta alusión al pan ganado para la familia con el sudor de su frente, y a los guardias como los infames, canallas, ladrones e indolentes que les impiden el "trabajo" a los buenos hombres, le otorga una carga moral, legitimadora y justificadora de la actividad. Justifica inclusive el uso de la tortura por parte de los contrabandistas para con los guardias:

Bien comandante de ladrones, dijo, ¿te acuerdas del tabaco que me robastes en días pasados? ¿Te acuerdas de mis súplicas para que no me hicieras aquel daño? ¿Te acuerdas que con el tabaco venían otros objetos que no eran de comiso y que te lo robaste tú con tus camaradas?... Pues bien canalla infame ladrón detestable ahora sabrás lo que es ser picaro y malvado.." 37 .

Eustorgio Martínez Fajardo, conocido como Eusmarfa, uno de los más importantes cronistas de la cotidianidad cartagenera de principios del siglo $\mathrm{XX}$, en sus interesantes notas porteñas se refería así del contrabandista:

Por una rara paradoja es ahora la ley la que piratea en el mar contra los proveedores clandestinos (...) Olfatean a la distancia el paquete clandestino, y empiezan a la caza marina (...). Faltaría saber si tenemos contextura moral para esos riesgos, entre los cuales no es de contar aquel de un balazo de los guardias en el golfo (...). ¿Cómo rescatar para el libro esta personalidad atrevida y misteriosa de nuestras costas libérrimas?"38.

Daniel Lemaitre, destacada personalidad de Cartagena, humanista, empresario, funcionario público, hasta el punto de ser alcalde de la ciudad, en sus famosos "Corralitos de Piedra", aborda de forma jocosa y desprevenida el tema del contrabando:

\footnotetext{
${ }^{36}$ Ibid., pp. 311-312. Las cursivas son nuestras.

${ }^{37}$ MADIEDO, Op. Cit, pp. 317-318.

${ }^{38}$ MARTÍNEZ FAJARDO, Eustorgio. Notas Porteños, Cartagena, Imprenta Departamental, vol. 4, 1943.
} 
(...) a lo mucho de cuando en cuando, salían fantasmas como "el Coche de otro Mundo" o "La Tolúa", pero estos aparatos olían siempre a tabaco de Virginia y a poco desaparecían convertidos en derechos de Aduana ${ }^{39}$.

El contrabando culturalmente revierte la racionalidad, desjerarquiza las relaciones sociales, resignifica, resemantiza los roles, como en la canción del maestro Escalona a su amigo contrabandista "Pipe" Socarrás, "barco pirata bandido, que Santo Tomás lo vea...”.

Otra de las prácticas transgresoras en la medida que afectaba la moral pública, presente en la sociedad cartagenera era la prostitución. En 1916 la Unión Comercial presenta una nota en la que insinúa la presencia de funcionarios públicos en casa de citas, donde se hacen bailes si el debido permiso, y cuando las autoridades se acercan para solicitarlo sale uno de los presentes a una hora que sería imposible conseguirlo y regresa con él mostrándolo a las autoridades:

(...) en la referida casa se hacen bailes en que concurren meretrices y caballeros de alta sociedad, efectuándose aquello sin previo permiso de la autoridad; y cuando algún agente se acerca en solicitud de la autorización expresada, sale en auto, ya a deshoras de la noche, cualquier señorito de la misma compañía y trae seguidamente una orden sin antes llenar los requisitos que a esa hora es imposible llevar a cabo $^{40}$.

Aquí, como en el contrabando, también participaban todos los sectores sociales de la ciudad de Cartagena. Los avisos que aluden a las drogas para la cura de las enfermedades venéreas, como el famoso "depurativo guardias", "La inyección V" y "La no es por nada" aparecen diariamente en los principales periódicos, sólo compiten en número y en frecuencia los avisos de remedios para la bronquitis, tuberculosis, etc.; junto con la disentería y la tuberculosis las enfermedades venéreas eran tema frecuente

39LEMAITRE, Daniel, Poesías y Corralitos de Piedra. Bogotá, Cofinorte, 1984, p. 218. 40A.H.C. La unión Comercial, 2 de junio de 1916, p. 4. Las cursivas son nuestras. 
de tesis de grado de los estudiantes de medicina de la Universidad de Cartagena.

\section{CARNAVAL EVENTO / CARNAVAL COTIDIANO}

Para una sociedad como la cartagenera, el carnaval era un elemento fundamental, que se organizaba con toda la anticipación del caso, la ciudad se paralizaba en sus actividades laborales, los periódicos no circulaban, y sólo había espacio y tiempo para el desenfreno. La participación de la élite no sólo se daba a través de la organización de los tradicionales bailes en el Club Cartagena, de igual forma se organizaban carrozas, desfiles de disfraces, batallas de flores, guerras de buscapiés en las calles, parques y plazas públicas de la ciudad.

Eran tan importantes los fiestas de carnaval que Belisario Díaz dentro de la fiebre de cine que invadiera a la ciudad a comienzos del siglo XX, filmó y proyectó el 20 de febrero de 1915, una película titulada "11 de Noviembre" en el Teatro Variedades. Como era de esperarse el teatro se llenó a reventar, y en medio del calor, estallaba la algarabía cuando se reconocía a algunos de los presentes en el filme. Otro carnaval novembrino se había armado en el Variedades.

Era común que se solicitaran a las autoridades respectivas prórrogas a las fiestas, con el ánimo de seguir bailando y bebiendo:

No sabemos si hay programa, pero nos aseguran que hay fondos suficientes para ofrecer al público algunos números buenos; que habrá una gran plaza de toros; que los bailes públicos principiarán temprano (...), bien por Cartagena alegre la cual en esta ocasión como en otras según síntomas piensa extraerle la quinta esencia las prórrogas clásicas ${ }^{41}$.

\footnotetext{
${ }^{41}$ A.H.C. “Otra Prórroga”, El Porvenir, Cartagena, 22 de noviembre de 1913.
} 
El carnaval como se observa era un fenómeno sumamente importante para la ciudad. Sin embargo, a pesar de toda la transgresión que allí se pueda presentar, toda la violación de las jerarquías establecidas, no deja de tener cierto control, se puede afirmar que es un espacio reglado por el poder, partiendo de un hecho tan simple como la escogencia de la junta que se encargue de su organización, que determina la forma en que deben ir los desfiles, los discursos que se pronuncian, los disfraces, los colores, la música, los bailes, etc., parece más bien un tiempo de gracia, un espacio tiempo de tolerancia en el cual se le permite al pueblo actuar de manera desbordada. Como el bufón de palacio que posee la libertad de mofarse del poder, pero sólo en el espacio del castillo, una vez, pierde su puesto, pierde también la impunidad para la burla. El poder en las sociedades modernas, le hace espacio al desorden y lo regla, lo controla, en cierta forma, adjudicándole un espacio tiempo ${ }^{42}$.

Lo interesante, es que para el caso de la ciudad de Cartagena, el desorden, la transgresión, no sólo se circunscribe al espacio tiempo del carnaval, este, desborda los límites espacios temporales. Mientras el poder oficial se mostraba, se ponía en escena a través de la solemnidad de las celebraciones patrias, de los discursos que reivindicaban nuestra noble descendencia española, de los sermones eclesiásticos, de las construcciones que marcaban imaginarios urbanos, más que la realidad, el poder representa lo que debería ser, se mira al espejo disfrazado y se devuelve una imagen falseada, la ciudad en su cotidiano vivir parecía un carnaval perpetuo. El contraste estará dado en la medida que para estas fechas, se está intentando llevar a cabo un proyecto de modernización, que tendría visos de parodia, en la medida en que sus preconizadores, no podían renunciar a las características culturales de la sociedad a la que pertenecían.

Lo que hemos pretendido mostrar es cómo Cartagena, a partir de una serie de procesos económicos, políticos y sociales, que sólo pueden ser mirados en la larga duración, crea unas características culturales, muy a tono con el Caribe insular. Una constante transgresión, que obliga al poder a negociar. Transgresión de la cual participan todos los sectores de la sociedad, sin

\footnotetext{
${ }^{42}$ BALANDIER, George, Op. Cit, pp. 66 y ss.
} 
embargo, a pesar de todo, los elementos de jerarquización social a partir del factor étnico, van a definir una sociedad con dinámicas de exclusión. La negación de lo negro y la alusión a aldeas africanas para referirse a las manifestaciones de los sectores populares, ligadas a la necesidad de mostrarse como una sociedad moderna, serán una constante en el discurso de las élites locales, "¿qué hacer con estos grupos de aldea, con todas estas actitudes que revelan atavismos deplorables?". Un aviso comercial impreso en la prensa de inicios del siglo XX nos da buena fe de lo anterior:

Permanentemente tengo a la venta (...) "bolas de cascarilla" para el cutis, que iguala las razas; oh! Las trigueñitas se ponen como circacianas!

No se olvide de este aviso; acuda donde Ricardo E. Román que la pondrá buena, bonita y blanca ${ }^{43}$.

\section{BIBLIOGRAFIA}

ANINNO, Antonio. "Soberanías en Lucha", en: De los Imperios a las naciones hispanoamericanas (comp), Forum International des sciences humaines, Zaragoza, 1994.

ARAUZMONFANTE, Celestino. El contrabando holandés en el Caribe, sigloXVIII, Caracas, Academia Nacional de Historia, 1986.

BALANDIER, George. El Poder en Escena, De la Representación del Poder al Poder de la Representación, Barcelona, Paidós, 1994.

BELL LEMUS, Gustavo. Cartagena de Indias, de la Colonia a la República. Bogotá, Fundación Guberek, 1991.

BENITEZ ROJO, Antonio. La isla que se repite, el Caribe en la perspectiva pos-moderna. Cuba, 1991.

43A.H.C. La Unión Comercial. Cartagena, 6 de agosto de 1915, p. 5. 
BURKE, Peter. La Cultura Popular en la Europa Moderna, Madrid, Alianza Editorial, 1991.

DON ANTONIO JUlí́n. La Perla de América. Provincia de Santa Marta, Bogotá, Biblioteca Popular Colombiana, 1951.

FALS BORDA, Orlando. Historia doble de la costa. Bogotá. Carlos Valencia Editores. 1987. Cuatro tomos.

FOUCAULT, Michel. Un diálogo sobre el Poder, Madrid, Alianza Editorial, 1985.

GRAHN, Lance. Comercio, Contrabando y Sociedad en la Nueva Granada, 1713-1763, Departamento de Historia, Universidad de Duke, 1985.

LYNCH, John. El Siglo XVIII, Historia de España, Barcelona. Crítica, 1991.

LEMAITRE, Daniel. Poesías y Corralitos de Piedra. Bogotá, Cofinorte, 1984.

MARTÍN-BARBERO, Jesús. De los Medios a las Mediaciones, Santafé de Bogotá, Convenio Andrés Bello, 1998.

MUÑERA CAVADIA, Alfonso. El fracaso de la nación. Región, clase y raza en el Caribe colombiano. 1717-1810. Bogotá, Banco de la República. Áncora Editores, 1998.

- "Comerciantes de Cartagena y el conflicto regional con Santafé a principios del siglo XIX". En: Historia y cultura. Revista de la facultad de Ciencias Humanas, Universidad de Cartagena, N 1. 1993.

. "Ilegalidad y fronteras". En Adolfo Meisel Roca (Editor).

Historia económica y social del Caribe Colombiano. Barranquilla, Uninorte. 1994.

MADIEDO, Manuel María. "El Contrabandista", en: Museo de Cuadros de Costumbres, Variedades y Viajes. Bogotá, Biblioteca Banco Popular, 1973.

MARTÍNEZ FAJARDO, Eustorgio. Notas Portenas, Cartagena, Imprenta Departamental, voi. 4, 1943.

MOUTOKIAS, Zacarías. Contrabando y control colonial. Buenos Aires entre el Atlántico y el espacio peruano en el siglo XVII. Buenos Aires, CEAL, 1989.

PALACIO DE LA VEGA, Joseph. Diario de Viaje entre los indios y negros de la provincia de Cartagena en el Nuevo reino de Granada, 1787-1788, Bogotá, 1955. 
POSADA CARBO, Eduardo. El Caribe colombiano, una historia regional. 1870-1950. Bogotá, Banco de la República - Áncora. 1998.

RAMOS, Feliciano. El contrabando inglés en el Caribe y el golfo de México, Sevilla Diputación Provincial de Sevilla, 1990.

TOVAR, Hermes. La estación del miedo o la desolación dispersa. El Caribe en el siglo XVI, Ariel, Santafé de Bogotá, 1998.

VILlALOBOS, Sergio. Comercio y contrabando en el Río de la Plata y Chile, Buenos Aires, Eudeba, 1965.

VIDAL ORTEGA, Antonino. Cartagena de Indias en la articulación del espacio regional caribeño, 1580-1640; La producción agraria, Lebrija (Esp.), Agrija ediciones, 1998. 